Priscila Anderson Ferreira

Barbara Almeida Soares Dias ${ }^{2}$

Katrini Guidolini Martinelli ${ }^{2}$

Lorrayne Belotti ${ }^{3}$

Marcelle Lemos Leal ${ }^{1}$

Erica Marvila Garcia ${ }^{3}$

\section{Analysis of exogenous food poisoning in Espírito Santo}

state

\title{
Análise das intoxicações exógenas por alimentos no estado do Espírito Santo
}

ABSTRACT | Introduction:

One can mix exogenous intoxication caused by food and food poisoning, because both events have similar symptoms and derive from the same contamination source, food. Objective: Analyzing notifications on exogenous food and / or water poisoning in Espirito Santo State from 2007 to 2016.

Methods: Descriptive study based on SINAN secondary data arranged in the TabNet platform of SUS Department of Informatics. The analysis was performed by means of absolute and relative frequency and by the incidence rate of exogenous intoxication. Results: October (424), January (399), December (389), February (388) and November (387) presented the largest number of cases. The Northern region stood out for the highest incidence of it in 2014 (58.6 / 100,000) and for the lowest one in 2016 (29.1 / 100,000). The

urban area accounted for approximately

$87 \%$ of the cases in 2016. In 2012, more than $80 \%$ of the final classifications

were based on confirmed intoxication -

376 cases were confirmed by attendance.

Conclusion: Exogenous intoxications are more frequent in October, January, December, February and November, in the

Northern region and in Urban zones. In addition, the clinical confirmation was more used in the ES in comparation with others methods. Despite the presented profile, lacke of important variables in the search sheet impaired the enhancement and dimension of the current result.

Keywords | Food poisoning; Food contamination; Illness notification.
RESUMO| Introdução: Erroneamente pode-se confundir a intoxicação exógena causada por alimentos com a intoxicação alimentar, isso porque as duas possuem similaridades nos sintomas e a mesma fonte de contaminação, o alimento. Objetivo: Analisar as notificações por intoxicação exógena causada por alimentos e/ou água, no Espírito Santo, no período de 2007 a 2016. Métodos: Estudo descritivo, baseados nos dados secundários do SINAN, dispostos na plataforma TabNet do Departamento de Informática do SUS. A análise foi realizada por meio da frequência absoluta e relativa e da taxa de incidência por intoxicação exógena. Resultados: Outubro (424), janeiro (399), dezembro (389), fevereiro (388) e novembro (387) apresentaram os maiores números de casos. A região Norte destacou-se por apresentar em 2014 (58,6/100.000) a maior incidência e em 2016 $(29,1 / 100.000)$ a menor incidência dos casos. A zona Urbana apresentou cerca de 87\% dos casos em 2016. Em 2012 mais de 80\% das classificações finais foram por intoxicação confirmada, com 376 casos confirmado pela clínica. Conclusão: As intoxicações exógenas são mais frequentes nos meses de outubro, janeiro, dezembro, fevereiro e novembro, na região Norte, e na zona Urbana. Além disso, a confirmação clínica foi a mais utilizada no ES. Apesar desse perfil apresentado, a ausência do preenchimento de variáveis importantes da ficha de investigação comprometeu o aprimoramento e a dimensão desse resultado.

Palavras-chave | Intoxicação alimentar; Contaminação de alimentos; Notificação de doenças.

${ }^{1}$ Universidade Federal do Espírito Santo. Vitória/ES, Brasil.

${ }^{2}$ Escola Nacional de Saúde Pública Sérgio Arouca, Fundação Oswaldo Cruz. Rio de Janeiro/RJ, Brasil. ${ }^{3}$ Universidade de São Paulo. São Paulo/SP, Brasil. 


\section{INTRODUÇÃO|}

O Ministério da Saúde ${ }^{2}$ define "intoxicação exógena como o conjunto de efeitos nocivos que revelam o desequilíbrio orgânico produzido pela interação de um ou mais agentes tóxicos com o sistema biológico. O agente tóxico é uma substância química, quase sempre de origem antropogênica, alterando uma ou mais funções, podendo provocar a morte (a intensidade da ação do agente tóxico será proporcional à concentração e ao tempo de exposição)". A intoxicação exógena CID 10: T65.9 foi incluída na lista nacional de notificação compulsória por meio da Portaria n. ${ }^{\circ}$ 204, de 17 de fevereiro de $2016^{3}$ devido ao impacto desses agravos no perfil de morbimortalidade da população, o que ampliou o escopo da vigilância epidemiológica e das proposições de promoção à saúde e prevenção ${ }^{4}$.

Dentre os diversos agentes tóxicos responsáveis pela transmissão da intoxicação exógena, destacam-se os alimentos e/ou água contaminados. A intoxicação exógena causada por alimentos e/ou água contaminados é proveniente da contaminação por substâncias químicas tóxicas tendo como via de transmissão o alimento e/ ou água contaminados. Portanto, devido ao agente tóxico, esta por sua vez é classificada como uma doença transmitida por alimentos (DTA) ${ }^{5}$. As DTAs causadas por exposição crônica a substâncias químicas são amplamente subnotificadas, ou seja, não há informações ou dados contundentes que informem a realidade da doença ${ }^{6}$.

Erroneamente se pode confundir a intoxicação exógena causada por alimentos com a intoxicação alimentar, isso porque as duas possuem similaridades nos sintomas e a mesma fonte de contaminação, o alimento. Porém, enquanto a intoxicação exógena por alimentos possui como princípio contaminante a substância química, a intoxicação alimentar é causada por agentes biológicos. Segundo o Ministério da Saúde, ${ }^{5}$ a intoxicação por agentes biológicos é provocada pela ingestão de toxinas formadas em consequência da acentuada multiplicação do micro-organismo patogênico no alimento, enquanto as intoxicações não bacterianas são ocasionadas por outros agentes não bacterianos, como nas intoxicações por metais pesados, agrotóxicos, fungos silvestres, plantas e animais tóxicos.

Estudo realizado por Santos \& Machinski Junior ${ }^{7}$ constatou que a região que mais notificou casos de intoxicação exógena por alimentos foi a sudeste, e que o Espírito Santo apresentou o maior número de exposições ao agente tóxico alimento ou bebida, configurando um grave problema de saúde pública para o Estado.

Diante do exposto, o objetivo deste estudo é analisar as notificações por intoxicação exógena causada por alimentos e/ou água, no Espírito Santo, no período de 2007 a 2016.

\section{MÉTODOS |}

Trata-se de um estudo descritivo, de série temporal, de base populacional, baseados nos dados secundários do Sistema de Informação de Agravos de Notificação - SINAN, dispostos no endereço eletrônico do Departamento de Informática do Sistema Único de Saúde do BrasilDATASUS na plataforma TabNet do Ministério da Saúde ${ }^{1}$. Foram analisados os casos de intoxicação exógena por alimentos e/ou água contaminados, notificados no período de 2007 a 2016 no Espírito Santo - Brasil.

Os dados foram extraídos por meio das Fichas de Notificação Compulsória de Intoxicação Exógena disponibilizada pelo Ministério da Saúde. As variáveis utilizadas foram: Agente Tóxico (alimento e água contaminados), Sexo (masculino e feminino), Mês do $1^{\circ}$ Sintoma, Ano do $1^{\circ}$ Sintoma (2011 a 2015), Faixa Etária (ignorado/ branco, <5 Ano, 5 a 14 anos, 15 a 39 anos, 40 a 64 anos, 65 a 79 anos e 80 e mais), Escolaridade (ignorado/ branco, analfabeto, $1^{\text {a }}$ a $4^{\mathrm{a}}$ série incompleta do ensino fundamental, $4^{a}$ série completa do ensino fundamental, $5^{a}$ a $6^{a}$ série incompleta do ensino fundamental, ensino fundamental completo, ensino médio incompleto, ensino médio completo, educação superior incompleta, educação superior completa e não se aplica), Zona de Residência (ignorado/ branco, urbana, rural e periurbana), Evolução (ignorado/ branco, cura sem sequela, cura com sequela, óbito por intoxicação exógena, óbito por outra causa e perda de seguimento), Critério de confirmação (ignorado/ branco, clínico-laboratorial, clínico-epidemiológico e clínico) e Classificação final (ignorado/ branco, intoxicação confirmada, só exposição, reação adversa, outro diagnóstico e síndrome de abstinência).

A análise foi realizada por meio do cálculo da média aritmética e da taxa de incidência por intoxicação exógena, dividindo-se o número de casos pela população residente e multiplicando-se por 100.000. Além disso, calculou-se a frequência absoluta e relativa de cada uma das variáveis. 
Como os dados são agregados e de domínio público, não houve necessidade de submeter o projeto de pesquisa à aprovação do Comitê de Ética em Pesquisa da Universidade Federal do Espírito Santo.

\section{RESULTADOS |}

No período de janeiro a dezembro dos anos de 2007 a 2016 foram notificados no Sistema de Informação de Agravos de Notificação 4.342 casos de intoxicação exógena causada por alimentos e/ou água contaminados no estado do Espírito Santo. Os meses que respectivamente apresentam maior número de casos foram: outubro (424), janeiro (399), dezembro (389), fevereiro (388) e novembro (387) conforme apresenta o Gráfico 1.

Em relação ao gênero, a maior incidência foi em homens, com uma tendência crescente ao longo do período (Tabela 1).

Conforme a Tabela 1, todas as faixas etárias apresentaram tendência crescente da incidência até o ano de 2014. Além disso, a faixa etária de $<5$ anos apresentou as maiores taxas de incidências com média de 15,67/100.00, principalmente no ano de 2013 (26,2/100.000), seguida pela faixa etária de 15 a 39 anos com média de 13,62/100.00. Quando analisadas as regiões de saúde, a região Norte foi a que apresentou maior incidência durante todo o período, entretanto todas apresentaram uma tendência crescente até o ano de 2013.

A raça/cor predominante nas notificações foi a parda, que apresentou tendência decrescente até o ano de 2012, enquanto a branca apresentou tendência crescente. Entretanto, a partir de 2013 os casos ignorados passaram a aumentar mostrando uma debilidade no preenchimento das fichas de notificação. Em relação à zona de residência, a zona urbana apresentou as maiores frequências, sempre acima de 60\% e com tendência crescente ao longo do período. Já a zona rural apresentou uma diminuição do número de notificações ao longo dos anos, alcançando aproximadamente $9,4 \%$ no ano de 2016 .

A maior proporção no tipo de exposição foi a agudaúnica, com percentuais próximos a 90\% até o ano de 2012. Entretanto, a partir de 2013 o percentual de ignorados aumentou consideravelmente, assim como o tipo de exposição crônica. Quanto ao tipo de classificação final, a maioria foi definida como intoxicação confirmada, seguida de reação adversa. Vale ressaltar que no ano de 2016 cerca de $30 \%$ dos casos foram assinalados como outro diagnóstico (Tabela 2).

Gráfico 1 - Distribuição das intoxicações exógenas, no Espírito Santo, no período de 2007 a 2016

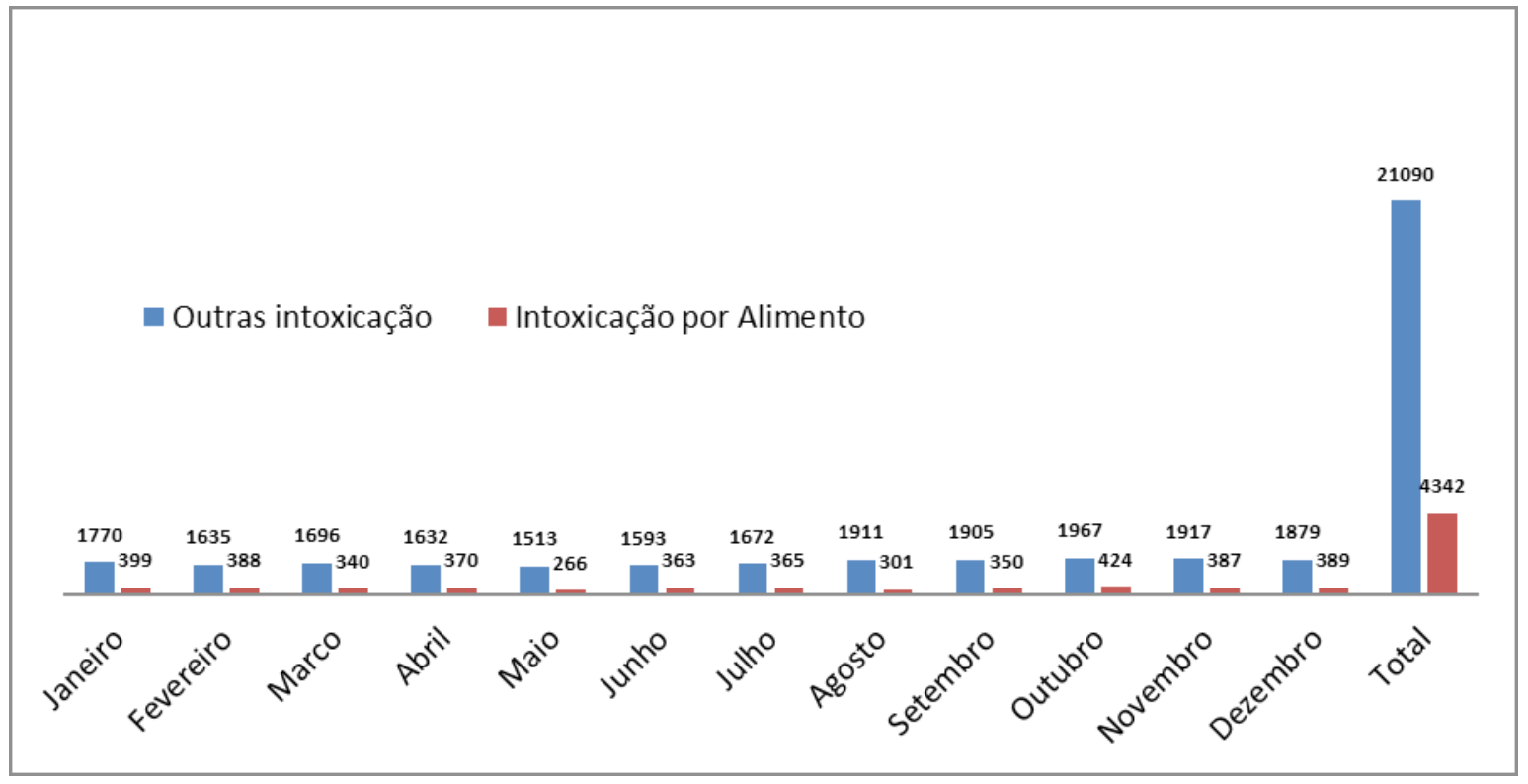

Fonte: Departamento de Informática do Sistema Único de Saúde do Brasil - Datasus. 
Tabela 1 - Distribuição da taxa de incidência por intoxicaşão exógena, no Espírito Santo, no período de 2007 a 2016

\begin{tabular}{|c|c|c|c|c|c|c|c|c|c|c|c|}
\hline \multirow{2}{*}{ Variáveis } & & \multicolumn{10}{|c|}{ ANO } \\
\hline & & 2007 & 2008 & 2009 & 2010 & 2011 & 2012 & 2013 & 2014 & 2015 & 2016 \\
\hline \multirow{2}{*}{ Sexo } & Feminino & 5,1 & 5,1 & 6,1 & 9,1 & 8,7 & 12,9 & 13,7 & 22,8 & 19,2 & 12,1 \\
\hline & Masculino & 6,2 & 5,6 & 6,9 & 12,0 & 10,9 & 13,1 & 15,2 & 23,1 & 17,6 & 12,5 \\
\hline \multirow{5}{*}{$\begin{array}{l}\text { Faixa etária } \\
\text { (Anos) }\end{array}$} & $<5$ & 7,6 & 6,6 & 9,1 & 12,7 & 13,2 & 18,4 & 26,2 & 24,6 & 24,1 & 14,2 \\
\hline & 5 a 14 & 7,6 & 6,0 & 8,5 & 9,9 & 7,9 & 14,7 & 15,4 & 22,7 & 15,9 & 7,1 \\
\hline & 15 a 39 & 5,7 & 5,7 & 7,0 & 11,8 & 11,2 & 14,3 & 15,5 & 26,8 & 22,1 & 16,1 \\
\hline & 40 a 79 & 4,0 & 3,9 & 4,0 & 8,8 & 8,3 & 9,6 & 10,5 & 18,4 & 14,6 & 10,0 \\
\hline & $\geq 80$ & 2,5 & 11,5 & 6,4 & 10,1 & 5,7 & 3,6 & 6,8 & 9,6 & 4,6 & 2,9 \\
\hline \multirow{4}{*}{ Região de Saúde } & Metropolitana & 0,6 & 0,3 & 0,9 & 1,5 & 2,5 & 5,2 & 6,9 & 19,6 & 14,8 & 12,2 \\
\hline & Sul & 5,4 & 7,5 & 7,5 & 14,0 & 14,7 & 11,8 & 11,9 & 10,2 & 9,8 & 5,0 \\
\hline & Norte & 42,3 & 36,2 & 42,8 & 51,7 & 36,9 & 51,0 & 25,1 & 58,6 & 43,9 & 29,1 \\
\hline & Central & 0,4 & 0,9 & 1,5 & 13,0 & 13,9 & 19,7 & 34,6 & 21,3 & 22,1 & 8,5 \\
\hline
\end{tabular}

Fonte: Departamento de Informática do Sistema Único de Saúde do Brasil - Datasus.

O critério de confirmação mais predominante foi o clínico, com percentuais acima de 70\%, seguido do critério clínicoepidemiológico. $\mathrm{Na}$ evolução da doença, a cura sem sequelas obteve as maiores proporções, sempre acima de 95\% durante todo o período. Vale destacar que o percentual de ignorados foi sempre abaixo de $3 \%$ (Tabela 2).

\section{DISCUSSÃO|}

Os resultados demonstraram que os meses de maior ocorrência dos casos de intoxicação exógena causada por alimentos/água contaminados foram de outubro a fevereiro, com maior ocorrência em menores de cinco anos, residentes na zona urbana e na região norte de saúde. Apesar do aumento da categoria ignorada no tipo de exposição, predominou o tipo aguda-única. O critério clínico se mostrou mais frequente no que diz respeito ao critério de confirmação, e as curas sem sequelas se destacaram quanto à evolução da doença.

Observou-se neste estudo que no período de outubro a fevereiro ocorreu o maior número de notificações por intoxicação exógena por alimentos. Esses meses são caracterizados por possuírem feriados e férias, o que ocasiona uma migração de pessoas para as regiões de praia e/ou montanhas, característica marcante do Estado do Espírito Santo. Nessas situações é muito comum ocorrerem intoxicações alimentares, em decorrência do elevado fluxo de pessoas e do aumento significativo do comércio eventual de alimentos. Isso sobressai o aumento da frequência da intoxicação alimentar causada por agentes biológicos que são responsáveis pela maioria dos casos de intoxicações alimentares ${ }^{8-10}$.

Além disso, esses meses apresentam condições climáticas favoráveis para proliferação de micro-organismos em alimentos, em que ocorre a perda de propriedades essenciais, acelerando a atividade enzimática das proteínas e a decomposição dos alimentos, configurando uma intoxicação alimentar provocada por agentes biológicos, e portanto justificando esse significativo aumento ${ }^{8-10}$.

Quando analisadas as faixas etárias, constatou-se que o grupo de $<5$ anos foi predominante. Isso provavelmente está associado ao fato de que crianças nessa faixa etária estão em fase de autodescoberta e curiosidade, além do processo imunológico ainda estar em construção. Portanto elas se tornam suscetíveis à intoxicação por substâncias químicas por intermédio dos alimentos do que outros grupos etários, conforme relatado em outros estudos ${ }^{11}$. Presgrave $^{12}$ afirma que os principais atendimentos de emergência envolvendo intoxicações são direcionados à assistência a crianças. E Werneck ${ }^{13}$ enfatiza que crianças menores de cinco anos de idade são mais suscetíveis às intoxicações acidentais, e o favorecimento à ingestão de substâncias químicas é decorrente da curiosidade característica dessa faixa etária. Esse risco ocorre devido ao fato de as crianças necessitarem de uma ingestão maior de 
事

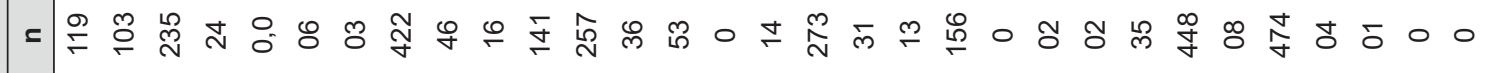
n) $=$ = 앙 J

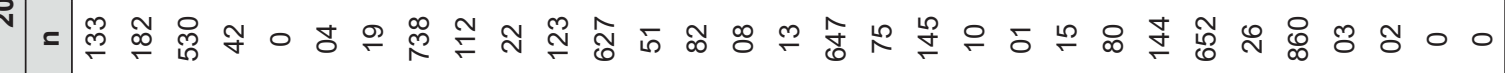

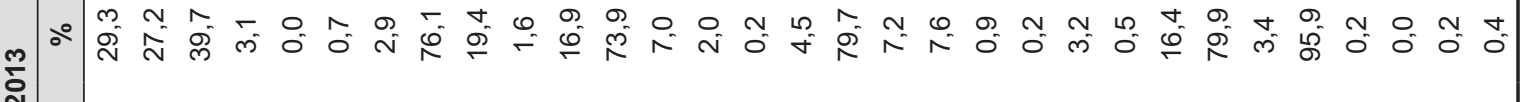

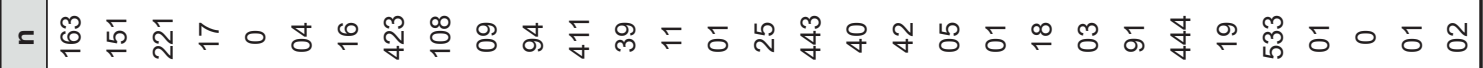

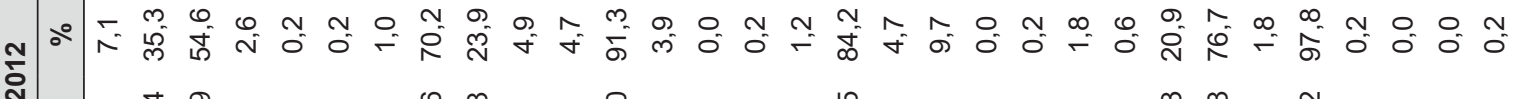
$=$ = $=$ F

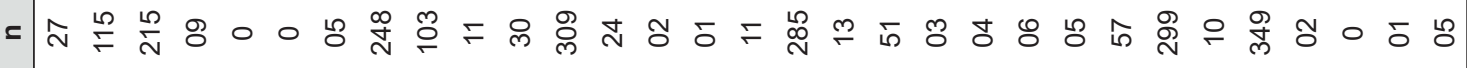

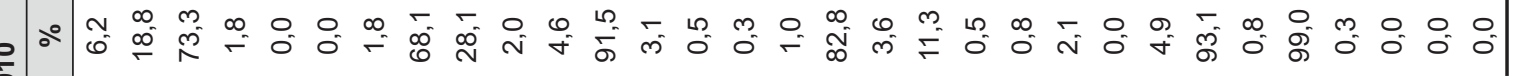
$=$ =

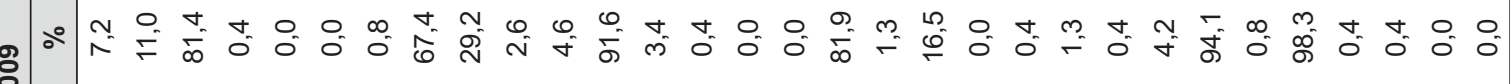

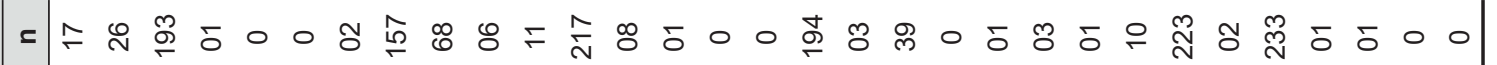

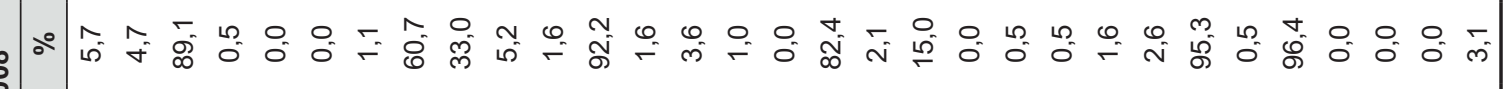
= = の

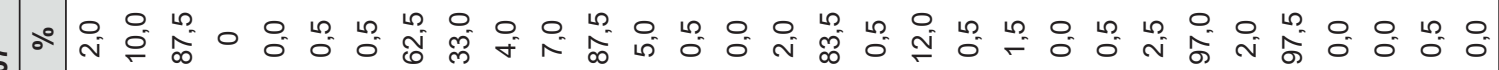
z 
alimentos para atender ao consumo de energia, bem como há uma variação elevada de absorção de muitos elementos químicos no organismo delas, além do fato de que muitos dos seus aspectos fisiológicos estão em fase de evolução ${ }^{14}$.

Em relação à zona de residência dos notificados, a urbana prevaleceu, apresentando expressivos números. Provavelmente alguns pontos podem ser sugeridos nesse resultado, por exemplo, o fato de o indivíduo residente em áreas urbanas tender a procurar com mais facilidade as unidades de saúde e, em consequência, a notificação do agravo. Estudo realizado sobre a exposição de agricultores a substâncias químicas constatou que, apesar da presença dos sintomas sugestivos de uma intoxicação, apenas $21 \%$ dos agricultores procuraram assistência médica enquanto $24 \%$ não tomaram nenhuma providência, e o restante optou pela automedicação ${ }^{15}$.

Além disso, como ainda persiste o confundimento entre a intoxicação exógena por alimento e a intoxicação alimentar, muitas pessoas podem ter sido classificadas equivocadamente pelos profissionais de saúde. Há prováveis imprecisões nas investigações dos casos, no que diz respeito à coleta de dados, registro de atendimento e possivelmente na digitação do SINAN, por parte dos profissionais de saúde responsáveis por cada uma dessas etapas ${ }^{16}$. Santana ${ }^{17}$ afirma que a "qualidade das informações geradas depende da qualidade dos profissionais envolvidos", portanto os profissionais necessitam de qualificação adequada para executar essas tarefas, pois há uma grande dificuldade em alcançar registros individuais confiáveis.

O tipo de exposição identificado mais predominante foi o aguda-única, que é caracterizado como aquela em que os organismos entram em contato com a substância química em uma única exposição, comumente nesse caso os efeitos são instantâneos, e o agente químico de modo geral é ligeiramente absorvido pelo organismo ${ }^{18,19}$. Desse modo, os casos procedem do provável consumo imediato do alimento contaminado com a substância química, e o indivíduo poderá ser exposto ao risco de contaminação com resíduos agrotóxicos se consumir frutas sem a devida higienização. Não obstante, na maioria dos casos, os resíduos químicos constatados nesses alimentos não suplantam os limites máximos aprovados para a ingestão do ser humano. Ademais, intoxicações provenientes de contaminação de alimentos por resíduos de agrotóxicos são relativamente incomuns, e os efeitos dessas substâncias no organismo por um longo período caracterizando acúmulo ainda são desconhecidos ${ }^{20,21}$.

Os ignorados apresentaram a segunda maior proporção no tipo de exposição, ou seja, o tempo e a frequência das exposições foramdesconhecidas ${ }^{19}$. Portanto diversas informações importantes não foram preenchidas durante a notificação, comprometendo dessa forma a identificação do tipo de exposição e em consequência o diagnóstico efetivo do agravo. Essas informações geram vieses nos resultados encontrados, visto que não é possível determinar se essas notificações de fato se enquadram na definição de intoxicação exógena por alimentos. Os sistemas de informações são essenciais para os progressos na assistência dos serviços de saúde, porém torna-se urgente a contenção e minimização de informações ignoradas que têm se destacado devido ao seu alto índice. Faz-se necessária a capacitação dos profissionais de saúde que proveem os dados fornecidos e a apreciação periódica do sistema de informação a fim de avaliar a sua funcionalidade e praticidade ${ }^{16}$.

A maioria das notificações foram classificadas como intoxicação confirmada, o que gera uma incoerência no processo de investigação, visto que uma grande proporção de informações ignoradas foi apresentada. Outro ponto importante é o destaque da reação adversa, que geralmente está associada e relacionada à intoxicação exógena causada por medicamentos, embora tenha ainda a possibilidade de ser provocada por alimentos. Nesse caso, os aditivos alimentares em dosagens equivocadas ou até mesmo uma intolerância de determinado organismo a tais substâncias, pode provocar uma intoxicação química tendo como via de transmissão o alimento. As altas frequências de reações adversas aos alimentos, nesse contexto, pode ser explicada se observada a exacerbada quantidade de antígenos alimentares, assim como a presença de aditivos e contaminantes químicos ou biológicos nos alimentos ${ }^{10,22}$.

Outro diagnóstico também foi bastante utilizado na classificação final, e esse dado pode ter sido influenciado pelas variáveis ignoradas, conforme identificado no resultado acima, o que gera preocupação, visto que essa classificação pode gerar grande impacto no contexto epidemiológico e de saúde da região e do indivíduo, afetando diretamente o planejamento e os cuidados dispensados. Em muitos casos, quando a classificação da intoxicação se torna inviável, alguns notificadores decidem classificar as variáveis disponíveis por termos 
mais abrangentes, portanto imprecisos, considerando que em sua maioria não possuem informações suficientes para embasamento, sobretudo quando ocorrem óbitos causados por produtos químicos ${ }^{23}$.

O quadro clínico foi predominante na definição dos casos de intoxicação exógena por alimento. Apesar de se tratar de um legítimo e relevante critério de confirmação, devido à constatação dos sintomas e efeitos que apontem e confirmem a presença da doença, nesse caso, por se tratar de uma intoxicação em decorrência de um alimento contaminado por produtos químicos, o critério clínico por si só se torna insuficiente para confirmar a doença. Em diversos casos, a ausência de diagnóstico laboratorial afeta a identificação do agente causador da intoxicação alimentar, pois ela apresenta sintomas e manifestações indefinidas e similares a outras doenças ${ }^{8}$.

Também identificado nesse estudo como um critério muito utilizado, o clínico-epidemiológico, tornase também insuficiente se o caso origem não tiver diagnóstico laboratorial confirmado, visto que, para fins de confirmação, ele seria o mais viável e seguro, pois possibilita a identificação por meio de exames do agente causador do agravo, e estão contemplados nesses exames os laboratoriais, de imagem e análises toxicológicas. Portanto, para identificação e caracterização da intoxicação, a investigação laboratorial é fundamental. A fim de delinear o factual problema, todos os parâmetros de investigação (epidemiológica, laboratorial e ambiental) existentes e acessíveis devem ser utilizados, principalmente em se tratando de suspeitas com substâncias químicas , $8,21,23-25^{\text {. }}$

$\mathrm{Na}$ evolução dos casos, destaca-se a grande proporção de indivíduos com cura sem sequelas, porém é possível observar algumas perdas de seguimento, e isso pode estar relacionado à deficiência na investigação e no acompanhamento dos casos, acarretando assim a produção de informações de saúde inconsistentes, interferindo diretamente no planejamento das ações. A análise dos dados tem por finalidade subsidiar as atuações quanto ao incentivo e cuidados inerentes à saúde pública, promovendo meios de prevenção de doenças e agravos ${ }^{1,824-26}$.

Pode-se observar que por vezes o descuido e inefetividade no preenchimento das notificações, assim como a incompreensão da definição desse agravo por parte dos profissionais de saúde envolvidos, dificultam e afetam diretamente a percepção acerca desse agravo, tanto no quesito clínico como no epidemiológico, corroborando equívocos na identificação, classificação e cuidados ao indivíduo acometido. Infelizmente, na área da vigilância e gerência dos programas de administração de agravos, ainda ocorre uma indeterminação no que diz respeito às atuações dos profissionais nas áreas técnicas e na execução das atividades, o que afeta diretamente na qualidade das informações da vigilância e consequentemente nas ações de prevenção e controle.

Muitos dos vieses de informações poderiam ser evitados com planejamento e execução de programas de educação para os profissionais da saúde responsáveis pelo atendimento e para o profissional responsável pela alimentação do sistema de informação, nesse caso o Sistema de Informação de Agravos de Notificação (SINAN). Isso porque o processo de informatização, assim como a definição de alguns agravos, ao longo dos anos sofreu consideráveis mudanças; a legislação que regulamenta a lista de doenças/agravos de notificação compulsória é recente, publicada em 17 de fevereiro de $2016^{3}$, porém as normas e rotinas determinadas para a utilização do SINAN são as mesmas desde 2007. Portanto, muitas informações se tornaram obsoletas, sendo imprescindível uma reavaliação e formulação de práticas concernentes às mudanças efetuadas.

\section{CONCLUSÃO |}

As intoxicações exógenas são mais frequentes nos meses de outubro, janeiro, dezembro, fevereiro e novembro, na região Norte, e na zona Urbana. Além disso, a confirmação clínica foi a mais utilizada. Apesar desse perfil apresentado, a ausência do preenchimento de variáveis importantes da ficha de investigação comprometeu o aprimoramento e a dimensão desse resultado.

\section{REFERÊNCIAS |}

1. Brasil. Ministério da Saúde. Sistema de Informação de Agravos de Notificação (SINAN). Brasília: Ministério da Saúde; 2006. p. 12-41.

2. Brasil. Ministério da Saúde. Guia de vigilância em saúde: volume único. 2. ed. Brasília: Ministério da Saúde; 2017. 
3. Brasil. Ministério da Saúde. Portaria no 204, de 17 de fevereiro de 2016. Define a Lista Nacional de Notificação Compulsória de doenças, agravos e eventos de saúde pública nos serviços de saúde públicos e privados em todo o território nacional, nos termos do anexo, e dá outras providências. Diário Oficial da União; 29 fev 2016.

4. Silva Júnior JBS, Gomes FBC, Cezário AC, Moura L. Doenças e agravos não-transmissíveis: bases epidemiológicas. In: Rouquayrol MZ, Almeida Filho N. Epidemiologia e saúde. Rio de Janeiro: Medsi; 2003. p.289311.

5. Brasil. Ministério da Saúde. Manual integrado de vigilância, prevenção e controle de doenças transmitidas por alimentos: volume único. Brasília: Ministério da Saúde; p. 39-44.

6. Chan M. Food safety must accompany food and nutrition security. The Lancet. 2014;384(9958), p.1910-1911.doi: 10.1016/S0140-6736(14)62037-7.

7. Santos AC, Machinski Junior M. Ocorrência de casos de intoxicação alimentar no Brasil, 2007-2012. In: Anais do 12. Congresso Latino Americano de Microbiologia e Higiene de Alimentos; 2014 out 12-15; Foz do Iguaçu, Brasil. São Paulo: Edgard Blücher; 2014. p. 193-4.

8. Almeida CF, Araújo ES, Soares YC, Diniz RLC, Fook SML, Vieira KVM. Perfil epidemiológico das intoxicações alimentares notificadas no Centro de Atendimento Toxicológico de Campina Grande, Paraíba. RevBrasEpidemiol. 2008; 11(1):139-46.

9. Amson GV, Haracemiv SMC, Masson ML. Ocorrências/ surtos de doenças transmitidas por alimentos (DTAs) no estado do Paraná - Brasil, no período de 1978 a 2000. CiêncAgrotec. 2006;30(6):7.

10. Barretto JR, Silva LR. Intoxicações alimentares [Internet] [acesso em 1 maio 2013]. Disponível em: URL: <http:// www.medicina.ufba.br/educacao_medica/graduacao/ dep_pediatria/disc_pediatria/disc_prev_social/roteiros / diarreia/intoxicacoes.pdf $>$.

11. Marques AJS. Perfil das intoxicações em crianças e jovens num serviço de urgência hospitalar. Covilhã. Relatório de Estágio [Mestrado em Ciências Farmacêuticas] - Universidade da Beira Interior; 2012.
12. Presgrave RF, Camacho LAB, Villas Boas MHS. Análise dos dados dos Centros de Controle de Intoxicação do Rio de Janeiro, Brasil, como subsídio às ações de saúde pública. Cad Saúde Pública [Internet]. 2009; 25(2):401-8.

13. Werneck GL, Hasselmann MH. Intoxicações exógenas em crianças menores de seis anos atendidas em hospitais da região metropolitana do Rio de Janeiro. RevAssoc Médica Bras. 2009;55(3):302-7.

14. Nacano LR. Avaliação da concentração de elementos químicos tóxicos na merenda escolar de crianças da cidade de Ribeirão Preto e estimativa de suas ingestões diárias. Ribeirão Preto. Dissertação [Mestrado em Ciências] Universidade de São Paulo; 2012.

15. Delgado IF, Paumgartten FJR. Intoxicações e uso de pesticidas por agricultores do Município de Paty do Alferes, Rio de Janeiro, Brasil. Cad Saúde Pública. 2004; 20(1):180-6.

16. Toledo ALA, Escosteguy CC, Medronho RA, Andrade FC. Confiabilidade do diagnóstico final de dengue na epidemia 2001-2002 no Município do Rio de Janeiro, Brasil. Cad Saúde Pública. 2006; 22(5):933-40.

17. Santana RAL, Bochner R, Guimarães MCS. Sistema nacional de informações tóxico-farmacológicas: o desafio da padronização dos dados.Ciênc Saúde Coletiva. 2011; 16(Supl. 1):1191-200.

18. Silva JM, Santos JR. Toxicologia de agrotóxicos em ambientes aquáticos. OecolBras Pernambuco. 2007; 11(4):565-73.

19. Prefeitura do município de São Paulo. Intoxicação: manual de vigilância programa municipal de prevenção e controle das intoxicações. São Paulo: Centro de Controle de Doenças, 2012.

20. Carvalho NL, Pivoto TS. Ecotoxicologia: conceitos, abrangência e importância agronômica. RevEletrPPGEAmb-CCR/UFSM. 2011; 2(2):176-92.

21. Jardim ICSF, Andrade JA, Queiroz SCN. Resíduos de agrotóxicos em alimentos: uma preocupação ambiental global (um enfoque às maçãs). Quím Nova. 2009; 32(4):9961012. 
22. Bricks LF. Reações adversas aos alimentos na infância: intolerância e alergia alimentar (atualização). Pediatria. 1994; 16(4):176-85.

23. Silva Filho J, Avelino AM, Albuquerque IMN, Pinto VPT. Intoxicação alimentar provocada por consumo de tapiocas contaminadas com carbamato em Sobral, Ceará, Brasil. Sanare. 2008; 7(1):50-5.

24. Mota DM, Porto EAS, Costa JA, França RFS, Cerroni $\mathrm{MP}$, Nóbrega AA, et al. Intoxicação por exposição à rapadura em três municípios do Rio Grande do Norte, Brasil: uma investigação de epidemiologia de campo. Saúde Soc. 2011; 20(3):797-810.

25. Maestri KCYO, Viana AFS, Lima AMC, Aguiar DCGB, Nogueira AM, Pereira PMP, et al. Intoxicações exógenas no município de Santarém-Pará nos anos de 2009 a 2013. Rev Universidade Vale Rio Verde. 2016; 14(1):647-56.

26. Schvartsman C, Schvartsman S. Acute poisoning in children. J Pediatr (Rio J). 1999; 75(8):244-50.

Correspondência para/Reprint request to:

\section{Priscila Anderson Ferreira}

Rua Desembargador Josias Soares, 99,

Centro, Anchieta/ES, Brasil

CEP: 29230-000

E-mail:pris.and.fern@gmail.com

Recebido em: 13/11/2018

Aceito em: 13/05/2019 